Endocrinol. Japon. 1959, 6 (3), 183 190

\title{
PEGULIAR RESPONSE OF TOAD LARVAE TO THIOUREA TREATMENT
}

\author{
HISAAKI IWASAWA
}

\section{Sado Marine Biological Station, Aikawa, Sado Island}

By application of goitrogens such as thiourea or thiouracil, the synthesis of thyroid hormone is disturbed, and progress of metamorphic changes in amphibian larvae is extremely inhibited. Furthermore decrease of thyroid hormone in the blood following this treatment brings over-secretion of TSH accompanied by changes of secretory levels of other tropic hormones from the hypophysis. Consequently those target organs such as the thyroid gland, gonad, adrenal gland are severely affected. Previously the author reported on some of these effects of goitrogens in several amphibian species. In the present paper the peculiar response of some organs of toad larvae to thiourea treatment is dealt with.

\section{MATERIAL AND METHOD}

Eggs of the toad, Bufo vulgaris formosus, were collected in the vicinity of Naoetu City on April 27. Tadpoles hatched from these eggs were used as materials. They had been kept in a $0.05 \%$ thiourea solution at room temperature from May 10, and were sacrificed and fixed in Bouin's solution on August 5, 60 days after the metamorphosis of controls. The solution in which tadpoles were kept was changed every other day. They were fed with boiled spinach. Throughout the periods of experiment, very few tadpoles died of disease or accidents. Sections were made in $12 \mu$ thickness, and stained with Delafield's hematoxylin and eosin. The acinar cell height of 20 follicles was measured in each animal, and the mean height was calculated.

\section{RESULTS}

According to the degrees of protrusion of the eye (exophthalmos), the fixed tadpoles were divided into 4 groups, namely Group A: severely protruded, Group B: considerably protruded, Group C: slightly protruded, Group D: normal (Figs. 1 and 2). Body size in each group is shown in Table 1.

The hypophysis showed extraordinary development, and there was found no evident difference in size among the groups exclusive of Group D. Histological examination revealed that remarkable hypertrophy and an increase in the number of basophilic cells which are considered as TSH- or GSH-secretory cells. The staining method employed in the present study, however, seemed to be unsuitable for more precise observation.

Difference in degree of enlargement of the eye-balls was clearly observed, and size of them was in the order, $A>B>C>D$ (Fig. 3). The same tendency

Received for publication July 1, 1959. 


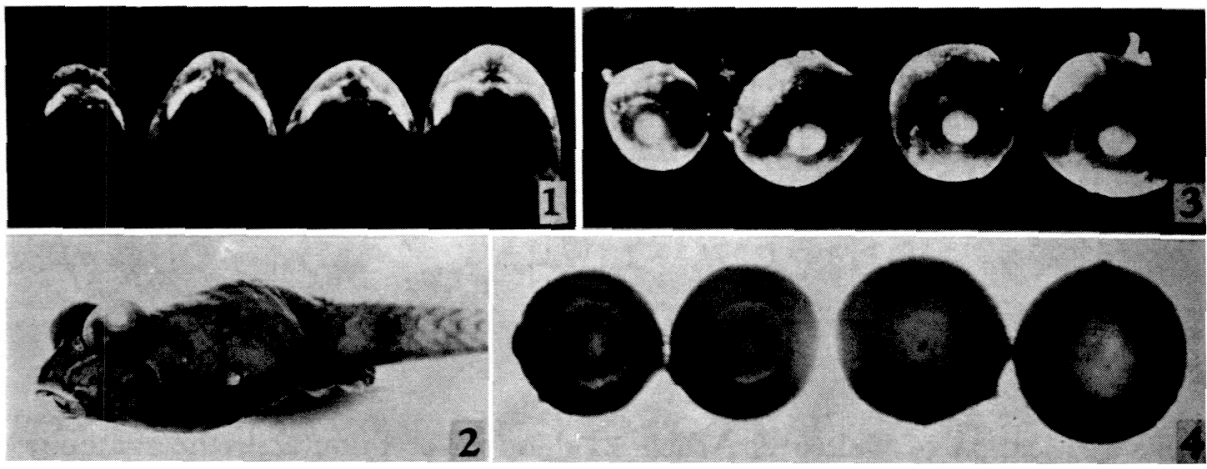

Figs. 1-4. According to degrees of protrusion of the eye, animals were divided into 4 groups. Right to left: Group A, Group B, Group C, Group D. 1. Head, 3. Eyeball, 4. Lens, 2. Side view of an eye-protruded animal (Group A).

Table 1. Body size in each group $(\mathrm{mm})$

\begin{tabular}{cccccc}
\hline \hline Group & $\begin{array}{c}\text { Total } \\
\text { length }\end{array}$ & $\begin{array}{c}\text { Body } \\
\text { length }\end{array}$ & $\begin{array}{c}\text { Body } \\
\text { breadth }\end{array}$ & $\begin{array}{c}\text { Tail-fin } \\
\text { height }\end{array}$ & $\begin{array}{c}\text { Hind-limb } \\
\text { length }\end{array}$ \\
\hline A & $37.2 \pm 1.8^{*}$ & $13.1 \pm 1.0^{*}$ & $7.1 \pm 0.7^{*}$ & $4.9 \pm 0.4^{*}$ & $5.2 \pm 0.5^{*}$ \\
B & $33.8 \pm 2.7$ & $12.0 \pm 0.8$ & $6.3 \pm 0.7$ & $4.7 \pm 0.5$ & $5.3 \pm 0.2$ \\
C & $34.9 \pm 1.9$ & $12.2 \pm 0.7$ & $6.5 \pm 0.7$ & $4.5 \pm 0.4$ & $5.1 \pm 0.6$ \\
D & $29.1 \pm 2.9$ & $10.4 \pm 0.3$ & $5.1 \pm 0.2$ & $3.8 \pm 0.5$ & $3.8 \pm 0.2$ \\
\hline
\end{tabular}

* Standard deviation

was also found in lens size (Fig. 4). According to microscopic observation, remarkable enlargement of the eye-ball cavity behind the lens was observed. Enlargement of the cavity was accompanied by a decrease in thickness of the retina. In the majority of the eye-protruded animals, especially in Group G, capillaries of the choroid were filled with abundant blood cells. Neither degenerative changes of connective tissue of the orbit nor infiltration with lymphocytes was observed at all.

The thyroid glands showed a marked increase in size in each group with the exception of $\mathrm{D}$, and size of them was in the order, $\mathrm{A} \geqq \mathrm{B}=\mathrm{C} \gg \mathrm{D}$ (Fig. 5). Histologically the glands of Groups A, B and C showed the picture of Struma parenchymatosa (Figs. 6-8). They consisted of a few large follicles and numerous small or crushed follicles lined with cubic or low-cylindrical epithelial cells. The former was generally filled with eosinophilic dense colloid, and sometimes a large amount of blood element was found in them. Hyperplastic papillae or infiltration with lymphocytes was scarcely observed. While the glands of animals belonging to Group D were slightly

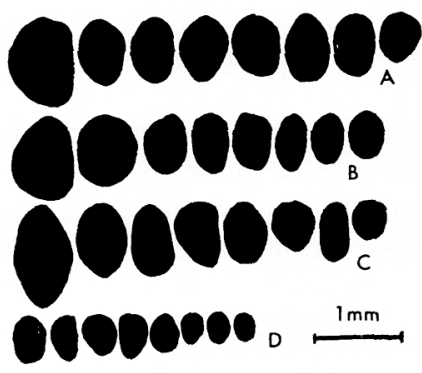

Fig. 5. Size of the thyroid glands. Camera lucida drawings (ventral view). A: Group A, B: Group B, C: Group C, D: Group D. 


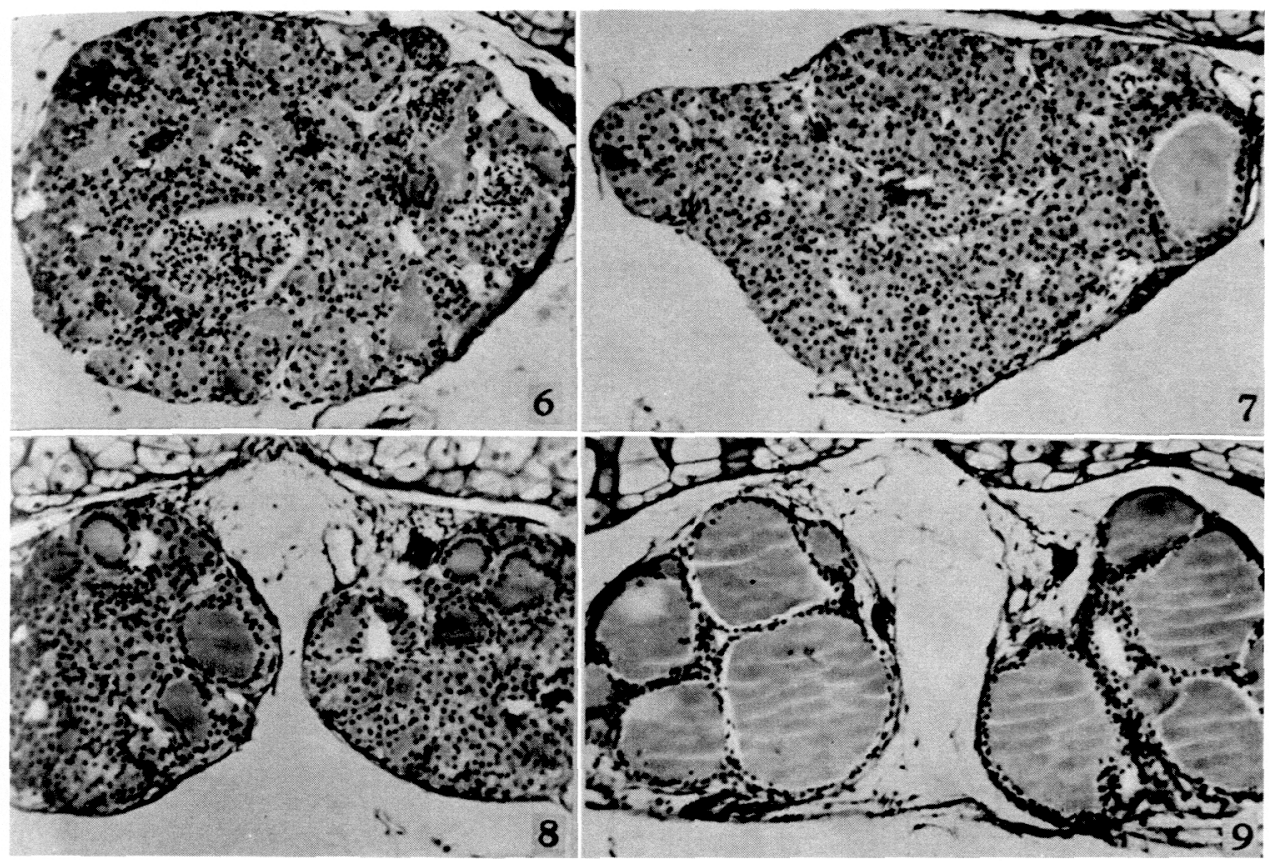

Figs. 6-9. Cross sections of the thyroid glands $(\times 100)$. 6-8. These pictures are observed in eye-protruded animals. 9. The picture of this type is observed in some of Group $D$.

Table 2. Epithelial cell height of thyroid follicles $(\mu)$

\begin{tabular}{|c|c|c|c|}
\hline A & B & C & $D$ \\
\hline $12.5 \pm 1.1^{*}$ & $12.9 \pm 1.0^{*}$ & $11.1 \pm 1.1^{*}$ & $9.0 \pm 1.4^{*}$ \\
\hline
\end{tabular}

* Standard deviation

activated or almost normal in histology (Fig. 9). Epithelial cell height of thyroid follicles is shown in Table 2.

Size of the ovaries was in the order, $A=B=C \gg D$. The same tendency was also conspicuous in the testes, viz. $\mathrm{A} \geqq \mathrm{B}=\mathrm{C} \gg \mathrm{D}$ (Fig. 10). Histological examination revealed that in the ovaries, a large number of auxocytes developed in various degrees were observed (Figs. 11-13), in the majority of animals, however, a few of them showed degenerative pictures. Group D was considerably inferior to the other groups in the development of auxocytes (Fig. 15). In some of the eyeprotruded animals, a large amount of connective tissue was observed in the medullary part of the ovaries (Fig. 14). In the testes, seminiferous ampullae were formed, and germ cell differentiation in Groups A, B and C was slightly progressed in comparison with that in Group D (Figs. 17-21). Bidder's organs of Groups A, B and $\mathrm{C}$ showed more or less degenerative changes, and such pictures were extremely conspicuous in Group D. That is, degenerating egg-like cells were 


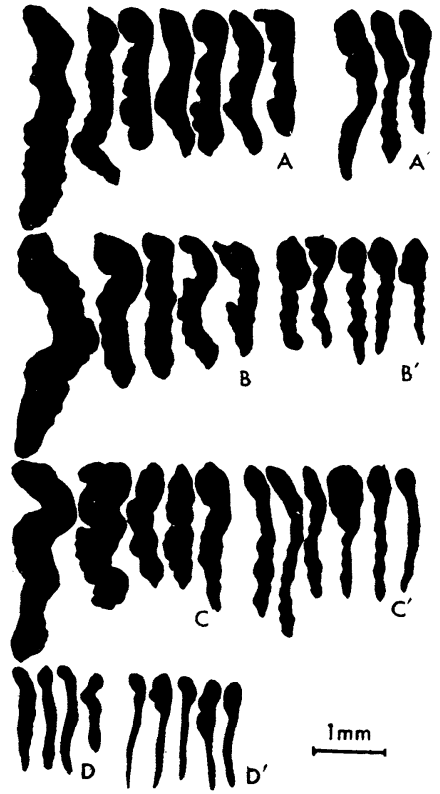

Fig. 10. Size of the right gonads of genetic females (A-D) and genetic males $\left(A^{\prime}-D^{\prime}\right)$. Camera lusida drawings (ventral view). $A, A^{\prime}$ : Group $A, B, B^{\prime}$ : Group B, C, $C^{\prime}$ : Group C, $D, D^{\prime}$ : Group $D$. found numerous in nearly all the animals, and remarkable amount of connective tissue was observed in the central part of the organs (Figs. 22-24). The gonads of the thiourea-treated animals were a bit smaller in size than those of young toads of the same age collected in the field. On the other hand, histological differentiation of the testes was more advanced, and that of the ovaries also seemed to be slightly more accelerated in the eye-protruded animals, although in some of the ovaries, histological pictures were somewhat degenerative. Development of Bidder's organs was extremely inhibited in the treated animals. As shown in Table 3 , the proportion of female to male was rather increased in Group A, the sex ratio as a whole, however, was approximately $1: 1$.

Table 3. Distribution of sex in each group

\begin{tabular}{cccc}
\hline Group & Male & Female & Total \\
\hline A & 3 & 9 & 12 \\
B & 8 & 6 & 14 \\
C & 10 & 8 & 18 \\
D & 5 & 4 & 9 \\
\hline Total & 26 & 27 & 53 \\
\hline
\end{tabular}

Figs. 11-26. Sagittal sections of the gonads (11-23: $\times 82,24-26: \times 240)$.

11-13. Ovaries (A). 14. Ovary. A large amount of connective tissue is observed in the medullary part. 15, 16. Growth-inhibited ovaries (D \& C).

17-19. Testes (B). 20. Testis. Considerable number of eggs are observed (B).

21. Growth-inhibited testis (D). 22. Degenerative Bidder's organ (o, C).

23, 24. Degenerative Bidder's organs $(\hat{O}, B) .25,26$. Abnormal cells found in Bidder's organs ( $\hat{o}, B \& D)$. 


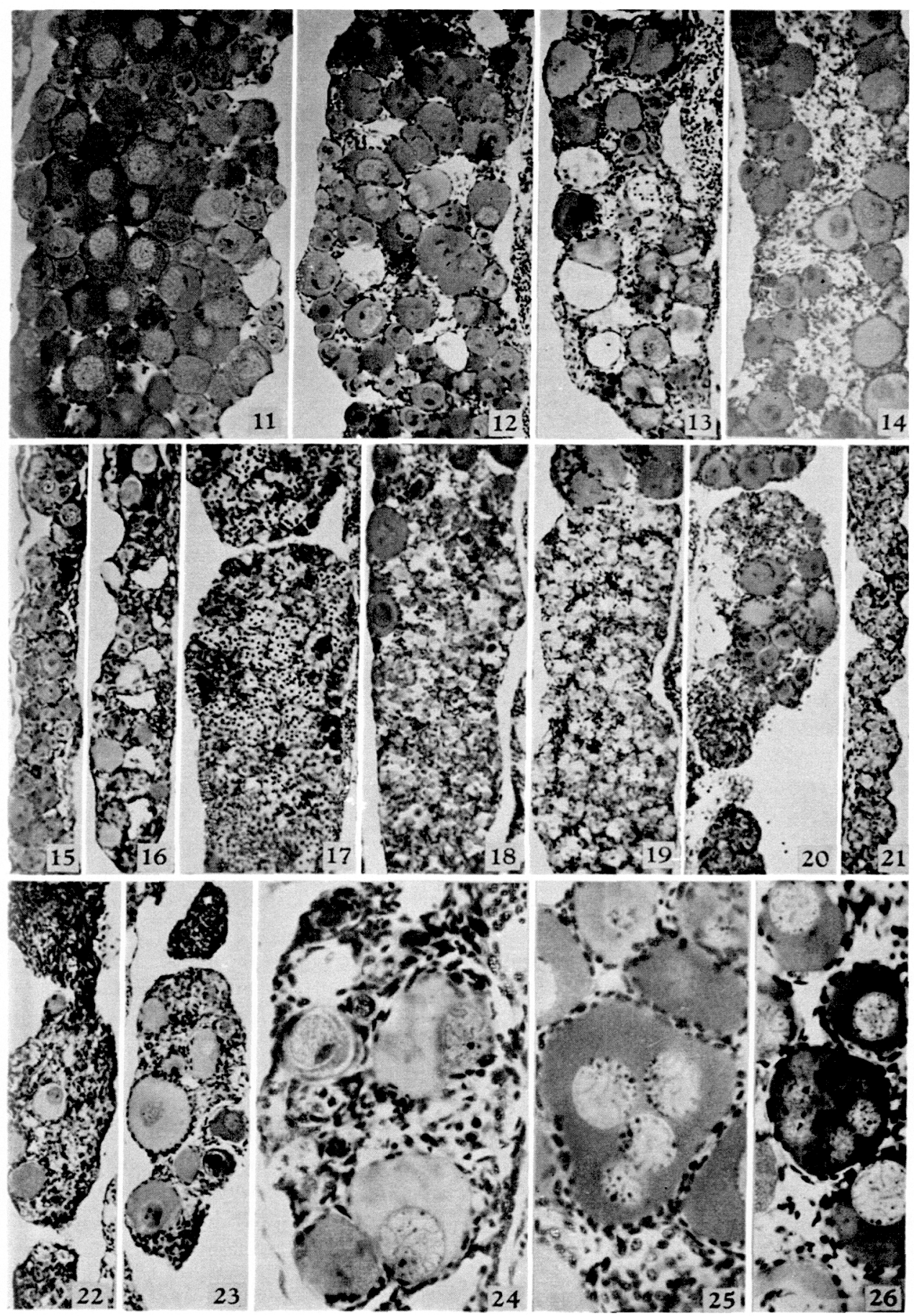




\section{DISCUSSION}

It is known that in some teleostean species, a state of exophthalmos, which is one of the symptoms of Graves' disease and is experimentally induced by injection of TSH in mammals, can be induced by application of thyroxin, thyrotropic preparations or goitrogens (Pickford and Atz, 1957). The response to these treatments, however, seems to differ depending on the species and on other conditions of the experiment. For instance, exophthalmos induced by treatment with thiourea was observed only in the case of Dentex dentex, and no such response occurred in the other teleostean species (Leloup and Olivereau, 1950).

Although in amphibians, numerous studies on the hypophysis-thyroid system have been done by many investigators, so far as the author knows, there seems to be no report in which experimental production of exophthalmos is described. The author has been studying on the effects of goitrogens for several years using some amphibian species as materials, but a state of exophthalmos has never been observed in any experiments. The explanation of this fact seems either that secretory levels of exophthalmos-producing substance (EPS) in the hypophysis are low or else that its release from the hypophysis is not closely correlated with that of $\mathrm{TSH}$, although species speciality in the hypophysis-thyroid system should also be taken into consideration. Struma parenchymatosa has been observed in toad larvae as the result of treatment with a $0.1 \%$ thiourea solution for 36 or 57 days (Iwasawa, 1957), and in such a case, exophthalmos would probably be produced by the more prolonged treatment.

It has been said that true exophthalmos in mammals is produced by an accumulation of fluid, mucoid substances or fat in the degenerated retrobulbar connective tissue owing to the direct action of EPS on the orbit. The same histological pictures have also been observed in exophthalmos Fundulus which were obtained by injection with hypophyseal substance (Albert, 1945). According to the present observation, however, exophthalmos was produced by a striking enlargement of the eye-ball cavity which was filled with vitreous humor. Interpretation of the result obtained by the author which is different from those of the previous investigators is difficult at present.

The author previously reported that masculinization and precocious germ cell differentiation were induced by treatment with goitrogens in tadpoles of Rhacophorus schlegelii (Iwasawa, 1955ab, 1958a-e), Rana japonica (Iwasawa, 1958ac), Rana temporaria ornativentris (Iwasawa, 1959), and Rana nigromaculata (Nakagawa and Iwasawa, 1958). In tadpoles of Bufo vulgaris.formosus, however, neither sex reversal nor prematuration was induced by the treatment (Iwasawa 1957). In the present experiment, gonadal differentiation was more accelerated in both sexes, especially in male, by thiourea treatment, although increase in gonadal size was not always accompanied by accelerated differentiation. Therefore in Bufo tadpoles, differentiation of the gonads seems to be inhibited in the first place, and then accelerated. On the other hand, development of Bidder's organ was always strikingly inhibited by the treatment. Such different responses between the ovary and Bidder's organ to the treatment are of interest. Masculinization of the genetic female induced by treatment with thiourea in 
several anuran species, did not occur in the present experiment, although there remains some slight possibility of masculinization caused by the more prolonged treatment. Hanaoka (1954) reported that acceleration of gonadal differentiation by thiourea treatment was remarkable in both Rana temporaria temporaria and Hynobius lichenatus but sex reversal of female to male occurred only in the former species. Consequently the following hypothesis may be elicited; masculinization of the genetic female by treatment with goitrogens easily occurs only in higher anurans (Rana, Rhacophorus), while in urodeles and lower anurans (Bufo), masculinization is difficult to occur. This phenomenon may be ascribed to the difference in the competence of the gonad-forming tissue in its broad sense to hypophyseal hormones. Concerning the mode of sex differentiation, higher anuran species used in the previous experiments as materials belong to so-called semidifferentiated type. Therefore it appears that further studies with species of the other types as materials are necessary to the criticism of the above-described hypothesis.

Comparison of the results obtained by thiourea treatment with those of thyroidectomy seems to be greatly significant. Allen (1918) reported that gonadal development of Rana pipiens tadpoles was not affected by thyroidectomy, but careful reading of his paper revealed that at least in male, differentiation of germ cells was undoubtedly accelerated. Hoskins and Hoskins (1919) showed that testicular development was remarkably accelerated by thyroidectomy in Rana sylvatica tadpoles. In these experiments, female individuals were found throughout the experimental periods, but composition of experimental groups was not suited to the discussion of the change of sex ratio after the operation. Murakawa and Koseki (1959) have recently reported that differentiation of the testes is remarkably accelerated in the thyroidectomized larvae of Hyncbius lichenatus, although sex ratio remains quite normal. Thus observations on thyroidectomized amphibian larvae are not contradictory to the results obtained by treatment with goitrogens, although there remains some points to be examined in detail.

\section{SUMMARY}

Tadpoles of Bufo vulgaris formosus were kept in a $0.05 \%$ thiourea solution for 87 days, and the effects on the eye-balls, thyroid glands and gonads were histologically examind.

Exophthalmos produced by a striking enlargement of the eye-ball was observed in different degrees in the majority of the treated tadpoles. The thyroid glands of those tadpoles remarkably increased in size, and grew into Struma parenchymatosa.

Gonadal differentiation was more advanced as compared with the frogs of the same age collected in the field, although degenerative changes were observed in the ovaries of some tadpoles. Development of Bidder's organ was considerably inhibited. Sex ratio was $1: 1$ as a whole, although severe exophthalmos was mostly observed in females.

Masculinization of the genetic female following treatments with goitrogens seems to occur easily only in higher anurans such as Rana and Rhacophorus, and such a reversal seems to be difficult to occur in urodeles and lower anurans. 


\section{REFERENCES}

Albert, A. (1945). Endocrinology 37, 389.

Allen, B. M. (1918). J. Exptl. Zool. 24, 499.

Hanaoka, K. I. (1954). Cytologia (Tokyo) 19, 182.

Hoskins, E. R. and H. M. Hoskins (1919). J. Exptl. Zool. 29, 1.

Iwasawa, H. (1955a). Endocrinol. Japon. 2, 263.

Iwasawa, H. (1955b). Endocrinol. Japon. 2, 269.

Iwasawa, H. (1957). Zool. Mag. 66, 425. (In Japanese with English summary)

Iwasawa, H. (1958a). Endocrinol. Japon. 5, 142.

Iwasawa, H. (1958b). J. Fac. Sci. Niigata Univ. Ser. II. 2, 189.

Iwasawa, H. (1958c). Sc:. Rep. Tohoku Univ. Ser. IV, 24, 55.

Iwasawa, H. (1958d). Zool. Mag. 67, 345. (In Japanese with English summary)

Iwasawa, H. (1958e). Endocrinol. Jopon. 5, 166.

Iwasawa, H. (1959). Zool. Mag. 68, 251.

Leloup, J. and M. Olivereau (1950). Compt. rend. soc. biol. 144, 772.

Murakawa, S. and T. Koseki (1959). Zool Mag. 68, 140. (In Japanese)

Nakagawa, Y. and H. Iwasawa (1958). Medicine and Biology 48, 140. (In Japanese)

Pickford, G. E. and J. W. Atz. The physiology of the pituitäry gland of fishes, New York Zoological Society, p. 161 (1957). 